\title{
Variable Speed Limit Signs: Control and Setting Locations in Freeway Work Zones
}

\author{
Wei Wang and Zeyang Cheng \\ College of Transportation, Jilin University, Changchun 130022, China \\ Correspondence should be addressed to Zeyang Cheng; chengzy14@mails.jlu.edu.cn
}

Received 18 October 2016; Revised 4 January 2017; Accepted 9 March 2017; Published 12 April 2017

Academic Editor: Pasquale Candito

Copyright (C) 2017 Wei Wang and Zeyang Cheng. This is an open access article distributed under the Creative Commons Attribution License, which permits unrestricted use, distribution, and reproduction in any medium, provided the original work is properly cited.

\begin{abstract}
Variable Speed Limit Sign (VSLS) Systems enable speed limits to be changed dynamically in response to traffic conditions so that traffic incidents can be reduced significantly on freeway work zones. In this paper, we examined how many and where VSLS are to be placed and the speed limits to be set and proposed a bilevel programming model to perform this decision making operation. The appropriate speed limits and deployments of VSLS were got by case study, and they were analyzed by a simulation to prove the empirical features of traffic breakdown at freeway work zones. Then the results of model comparison and simulation evaluation illustrate that the proposed method outperforms existing models in terms of maximizing information benefit and minimizing average queue length, total delay, and total stop frequency on the freeway work zone.
\end{abstract}

\section{Introduction}

Uneven velocity distribution is a major reason that contributes to incidents (e.g., traffic accident or congestion) in freeway work zones. In freeway work zones, the speed of vehicles will become discrete from upstream section to downstream section because of the temporarily closed lane, which will cause a series of traffic behaviors like lanechanging, slowing down suddenly, and car-flowing. So once the incident happens, these behaviors may lead to a secondary accident or a sharp decline of traffic capacity of freeway work zones [1]. Hence, it is of importance to perform effective speed limit control in freeway work zones.

"Variable Speed Limit Sign (VSLS) Control" is an effective traffic control technique that has been used in freeway work zones for recent years [2-5], and it is arousing more and more research interests. VSLS control in this paper involves the use of portable road signs that can be adjusted to display speed limits that are suitable to the immediate traffic conditions on the road. Researches about VSLS control are mainly concentrated in two aspects in the past: one aspect is to primarily reflect the effects of the control, that is, use the actual data about freeway work zones to evaluate the changing of drive behaviors (e.g., the decrease of speed, delay and queue length) or collision risk, and then to further evaluate the positive effect of VSLS control. The second aspect is to study the speed limits or the deployments of VSLS, where the estimation about accident risk and traffic condition will be got by optimizing the speed limit values and deployments of VSLS.

There has been considerable research work on the first aspect. A number of scholars (e.g., Mcmurtry et al. [6]; Lu et al. [7]; Lin et al. [8]; Ma et al. [9]) have attempted to establish some models to improve traffic conditions, and their results show that the effective VSLS control of freeway work zones can decrease speed and total time delay and improve traffic flow efficiency, respectively. While some others (e.g., AbdelAty et al. [10]; Allaby et al. [11]; Abdel-Aty et al. [12]; Fudala and Fontaine [13]) have conducted similar studies on traffic safety, and they found that VSLS control in freeway work zones can effectively reduce the collision risk and improve safety. These studies generally provide useful information on crash risk and safety of vehicles at freeway work zones. However, the specific speed limits of VSLS and their setting ways have not been well explored. In the second aspect, the relevant literatures are less than the first aspect. Speed limits of VSLS have been studied by several researches (e.g., Yu et al. [14]; Cao et al. [15]; Jia et al. [16]); experimental results 


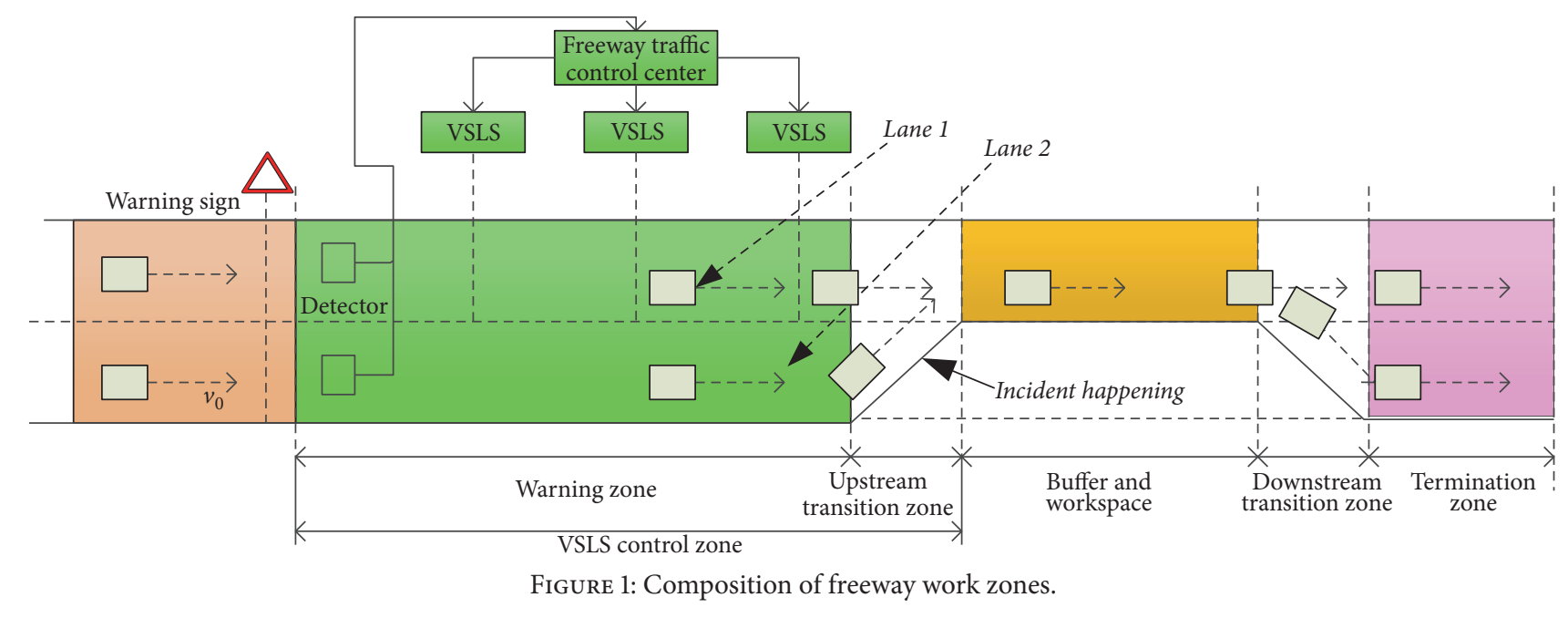

show that the optimized speed limits can reduce vehicle speed and enhance safety. Other studies (e.g., $\mathrm{Pu}$ et al. [17]; Ni and Liu [18]) have focused on the locations of VSLS, and the best appropriate locations of VSLS were determined by diverse methods like traffic-wave theory and mathematical programming model.

The above literatures have studied the speed limits or deployments of VSLS independently, while these theoretical methods are still the classical traffic theories which have been criticized in some latest reviews $[19,20]$ because of failing to consider the empirical nucleation nature of traffic breakdown at freeway work zones. Only very few speed limit control methods like the approach in [21] are consistent with the empirical nucleation nature of traffic breakdown at road bottlenecks. Hence, in this paper, the empirical nucleation nature of traffic breakdown is considered when studying the speed limit control method of freeway work zones, which would be consistent with the actual traffic conditions of freeway work zones, on the basis of which the comprehensive effect (i.e., the combination of speed limits and deployments of VSLS) that used to be analyzed less is studied in this paper.

In this paper, the main idea is to explore the comprehensive control effect of speed limit values and deployments of VSLS. On the basis of the above studies, we attempt to propose a bilevel programming model to seek for the best suitable speed limits and the corresponding locations of VSLS. The first object of the bilevel programming model is to optimize the numbers and speed limit values of VSLS by establishing a minimum comprehensive accident rate model. The second object is to optimize the locations of VSLS by solving the improved maximum information benefit model.

The remainder of this paper is organized as follows: In Section 2, methodology is proposed which includes three parts, that is, introduction of freeway work zones, traffic flow characteristic analysis of freeway work zones that combined the "three-phase traffic theory," and model development (includes the bilevel programming model and its two objective functions). In Section 3, case study is implemented, which includes the optimization of objective function 1 by exhaustive method and optimization of objective function 2 by genetic algorithm. In Section 4, a model comparison and simulation evaluation are performed. In Section 5, a brief review of this paper and the future research are presented.

\section{Methodology}

This section first introduces the freeway work zone and then describes model development, that is, the bilevel programming model and its two objective functions. The first objective function is a comprehensive accident rate model, and its influencing factors are the numbers and speed limit values of VSLS; that is, the comprehensive accident rate will be different according to various numbers of VSLS and its speed limit values. Our goal is to find the appropriate numbers and speed limit values of VSLS which can minimize the comprehensive accident rate. The second objective function is a maximum information benefit model in which the different locations of VSLS are influencing factors; that is, the best appropriate locations of VSLS should correspond to the largest information benefit. After that, the model comparison and simulation evaluation will be proposed in Section 4 to verify the superiority of our proposed model.

2.1. Freeway Work Zone. According to "Freeway Maintenance Safety Operating Procedures (JTGH30-2004)" of China, freeway work zones contain six parts: warning zone, upstream transition zone, buffer, workspace, downstream transition zone, and termination zone, as shown in Figure 1. In this paper, the type of freeway work zone is a two-lane freeway with its outside lane closed (lane 2), and the length of the work zone is no more than $5 \mathrm{~km}$ and the traffic capacity is $4000 \mathrm{veh} / \mathrm{h}$. The warning zone and upstream transition zone are considered as the targeted VSLS control zone. The warning sign is set up at the start of control zone to warn the drivers that they will enter into the work zone and advise them to slow down in advance; then several VSLS are set up in the upstream section of the work zone to gradually decrease the vehicle speed (here the speed has been reduced one time under the effect of the warning sign) approaching the work zone and to maintain a smooth traffic flow. Traffic detectors are set downstream of the warning sign to detect traffic volume and speed. In the study, we denote the initial 


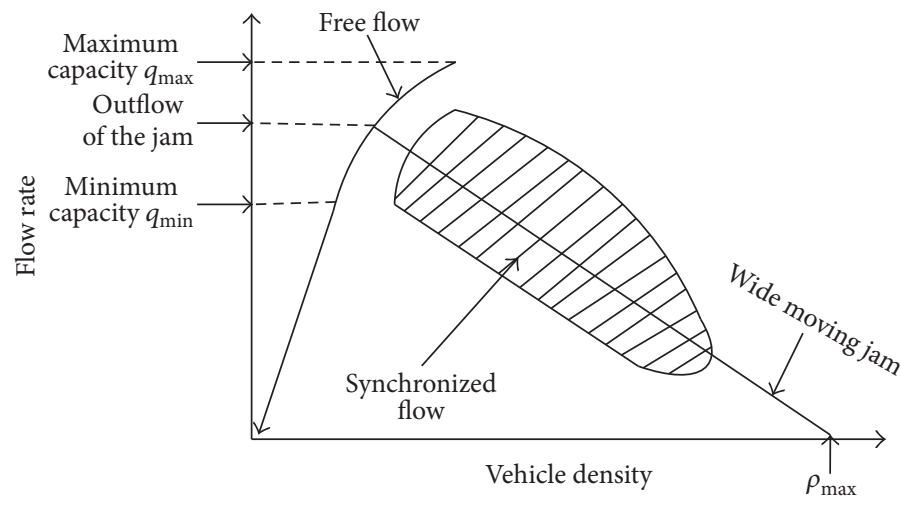

FIgURE 2: Three-phase traffic theory model of bottlenecks.

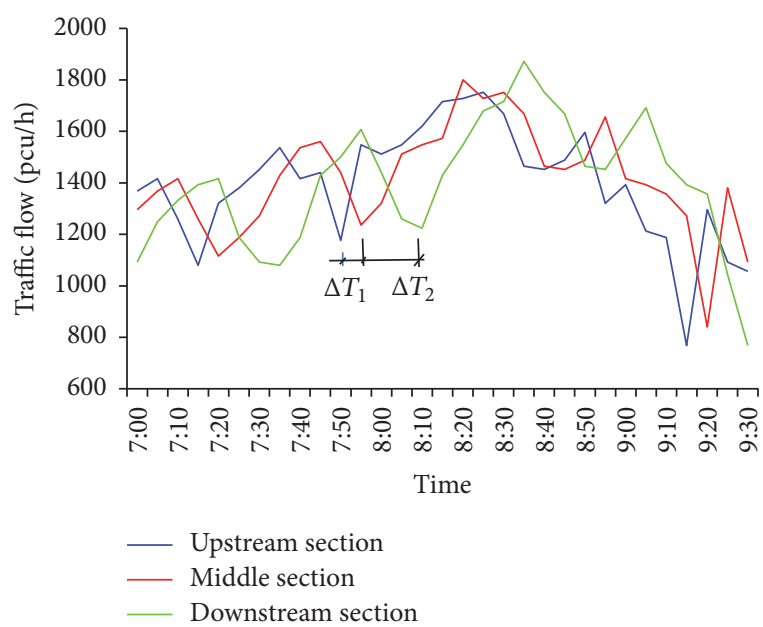

(a) Traffic characteristics of longitudinal section

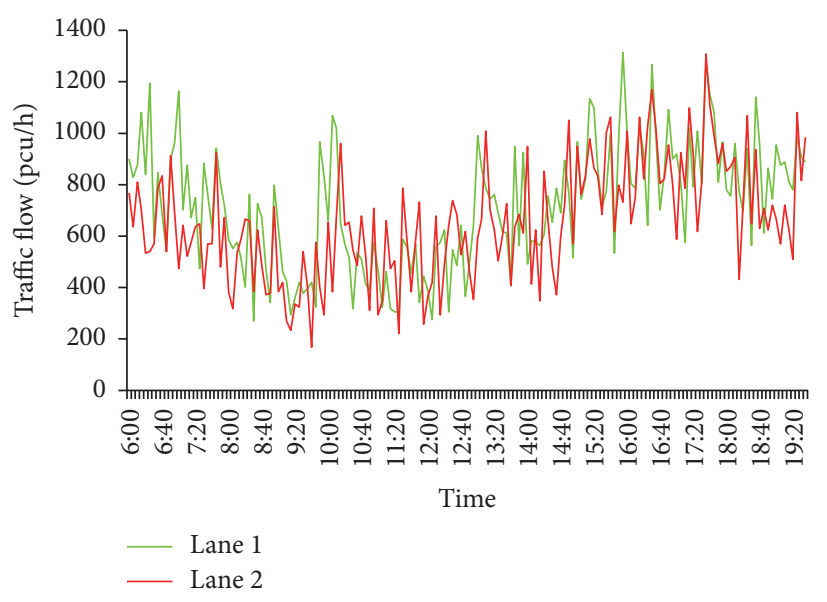

(b) Traffic characteristics of lateral section

FIGURE 3: Temporal-spatial characteristics of traffic flow.

speed of all vehicles entering into VSLS control as $v_{0}$ ( $v_{0}$ could be close to $60 \mathrm{~km} / \mathrm{h}$ under the effect of warning signs in the real conditions, and this will be mentioned in Section 3.1); then the VSLS control principle is as follows.

Assuming that an incident happens at the upstream transition zone at a certain time, then the volume and speed collected by detectors are transmitted to the traffic control center and then the relative control models, that is, the two objective functions of the bilevel programming model, are applied to determine the VSLS numbers, the speed limits, and VSLS locations. And the speed limit values can be adjusted dynamically, and then they will be allocated to the corresponding VSLS, and the numbers and locations of VSLS can be also adjusted dynamically.

2.2. Traffic Flow Characteristic Analysis of Freeway Work Zones. Traffic flow at freeway work zones has a very complicated feature, the classical traffic flow theory includes two phases, that is, smoothing and blocking flow, which cannot demonstrate the actual characteristics of traffic flow perfectly at freeway work zones sometimes. So the "three-phase traffic theory" was proposed by Kerner [22, 23] to analyze the actual state of traffic flow at freeway bottlenecks effectively.
Kerner pointed out that "three-phase traffic theory" includes three phases: (1) free flow; (2) synchronized flow; (3) wide moving jam. And the first phase transition from free flow to synchronized flow phase ( $F \rightarrow S$ transition) explains the empirical features at bottlenecks [21]. Figure 2 shows the model of "three-phase traffic theory."

This section analyzes the actual traffic characteristics of freeway work zones from temporal-spatial perspective. The traffic volume is selected from the freeway of Shandong, China, the detected sections include K12+875, K14+795, $\mathrm{K} 16+985$, and detected time is from October 20, 2014, to October 26, 2014. The spatial characteristics are divided into two aspects, one is lateral aspect (the adjacent lanes, e.g., lane 1 and lane 2 of $\mathrm{K} 12+875$ ), and the other is the longitudinal aspect (the adjacent sections, e.g., the upstream section $(\mathrm{K} 12+875)$, the middle section $(\mathrm{K} 14+795)$, and the downstream section $(\mathrm{K} 16+985))$. Temporal-spatial characteristics of traffic flow and speed at freeway work zone of Shandong are shown in Figures 3 and 4.

Figures 3 and 4 illustrate that the traffic flow can not only present the real-time and dynamic features but also show the similarity features. Each road in freeway is interconnected, and the traffic state of each adjacent section influences the 


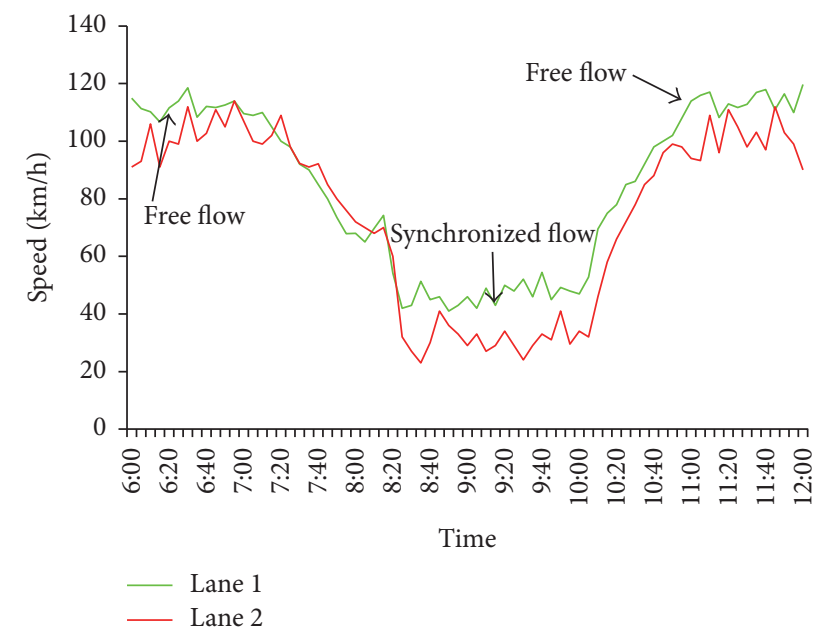

FIGURE 4: Speed characteristics of lateral section.

other. Figure 3(a) shows that there is a hysteresis of traffic status upstream and downstream, $\Delta T_{1}$ is the hysteresis between upstream and middle section, and $\Delta T_{2}$ is the hysteresis between middle and downstream section. So the traffic state is not always free flow, it has a periodic change from free flow to synchronized flow and then to jam. When vehicles are close into freeway work zones, the traffic flow presents the transition from free flow to synchronized flow and then could transfer into the transition from synchronized flow to jam if an incident occurs. When vehicles stay away from work zones, the traffic flow may return to free flow. Figure 3(a) shows that the normal propagation of traffic flow is from upstream section to downstream section, while in crowded areas or when incidents happen, the propagation can be backtracking from downstream section to upstream section where the state may be the transition from synchronized flow to jam. Figure 4 shows the speed change under blocked condition; the speed distribution at freeway work zones presents the empirical nucleation nature of traffic breakdown at road bottlenecks.

\subsection{Model Development}

2.3.1. Objective Function 1: Minimizing Comprehensive Accident Rate. Traffic accidents happen frequently at freeway work zones. In general, the accident rates of freeway work zones in northeast China are 2.7 times as high as that in ordinary road [24], because in freeway work zones, the speed of vehicles is inappropriate. Therefore, it is necessary to explore the relationship between the discrete speed and accident rate. Before the comprehensive accident rate model, several researches about the accident rate models (e.g., the models proposed by $\mathrm{Pu}$ et al., Zhong et al., and Hou et al.) have been proposed, and these studies illustrate that the main factors which influence the accident rate are vehicle speed, interval speed difference, and standard deviation of speed, respectively.

$\mathrm{Pu}$ et al. have studied the relationship between vehicle speed and accident rate by analyzing the actual freeway data [17]. They finally obtained the following model:

$$
\begin{aligned}
C_{1}\left(v_{i}\right)= & \frac{99.7488}{v_{f}^{4}} v_{i}^{4}-\frac{199.4976}{v_{f}^{3}} v_{i}^{3}+\frac{128.6364}{v_{f}^{2}} v_{i}^{2} \\
& -\frac{28.8876}{v_{f}} v_{i}+2.7091,
\end{aligned}
$$

where $C_{1}$ is accident rate. $v_{i}$ is vehicle speed, and $v_{f}$ is free speed. In the model, the correlation coefficient $R_{1}$ is 0.554 and the decision coefficient $R_{1}{ }^{2}$ is 0.307 which shows that only $30.7 \%$ of the data has been effectively fitted.

Zhong et al. have studied the relationship between interval speed difference and accident rate [25]. Finally they discovered the following relationship:

$$
C_{2}\left(\Delta v_{i}\right)=0.498 \times e^{\Delta v_{i}},
$$

where $C_{2}$ is accident rate and $\Delta v_{i}$ is speed difference: $\Delta v_{i}=$ $v_{i}-v_{i+1}$. The correlation coefficient $R_{2}$ is 0.358 , and the decision coefficient $R_{2}^{2}$ is 0.128 .

Furthermore, Hou et al. have studied the relationship between speed standard deviation and accident rate [26]. By analyzing the existing freeway data, the following model was found.

$$
C_{3}(\delta)=-35.472+16.435 \ln (\delta),
$$

where $C_{3}$ is the accident rate and $\delta$ is standard deviation of speed: $\delta=\sqrt{\sum_{I=1}^{N}\left(v_{i}-\sum_{I=1}^{N} v_{i} / n\right)^{2} /(n-1)}$. In the model, the correlation coefficient $R_{3}$ is 0.986 , and the decision coefficient $R_{3}{ }^{2}$ is 0.972 , which explains that the goodness of fit in this model is the best.

The above models considered single factor only (e.g., speed, speed difference, or speed standard deviation) in their respective study. By analyzing (1), (2), and (3), we find that the speed standard deviation is the most influential factor among speed, speed difference, and speed deviation. Meanwhile, we can conjecture that these factors may influence one another. Hence, it is necessary to study the total and comprehensive influence of the three factors; at the same time, we should also make sure that the empirical nucleation nature of traffic breakdown at the freeway work zone is consistent with our models. So the new model is proposed by forming a linear combination of the three factors, and it is shown as follows:

$$
C_{123}=\beta_{1} C_{1}\left(v_{i}\right)+\beta_{2} C_{2}\left(\Delta v_{i}\right)+\beta_{3} C_{3}(\delta),
$$

where $C_{123}$ is comprehensive accident rate, $\beta_{1}, \beta_{2}$, and $\beta_{3}$ are weights of the three models, respectively, that is, $\beta_{1}=R_{1}{ }^{2}$ / $\left(R_{1}{ }^{2}+R_{2}{ }^{2}+R_{3}{ }^{2}\right), \beta_{2}=R_{2}{ }^{2} /\left(R_{1}{ }^{2}+R_{2}{ }^{2}+R_{3}{ }^{2}\right)$, and $\beta_{3}=R_{3}{ }^{2} /$ $\left(R_{1}^{2}+R_{2}^{2}+R_{3}^{2}\right)$, and $C_{1}\left(v_{i}\right), C_{2}\left(\Delta v_{i}\right)$, and $C_{3}(\delta)$ are the three independent models which are the same as (1), (2), and (3).

In order to explore problems further, we presume that all the vehicles drive at the speed of VSLS at the control zone. As a result of the above analysis, a minimum comprehensive accident rate model is established as follows:

$$
\begin{array}{ll}
\operatorname{Min} & \left(C_{123}\right) \\
& =\operatorname{Min} \sum_{i=1}^{n}\left(\frac{\left(\beta_{1} C_{1}\left(v_{i}\right)+\beta_{2} C_{2}\left(\Delta v_{i}\right)\right)}{n}+\beta_{3} C_{3}(\delta)\right),
\end{array}
$$




$$
\begin{array}{ll}
\text { s.t. } & v_{i}=\{20,30,40,50,60,70,80,90,100\} \\
& v_{i} \leq v_{k} \\
& v_{i}-v_{i+1} \leq 20
\end{array}
$$

where $i$ are numbers of VSLS, $v_{i}$ and $v_{i+1}$ are speed of the $i$ th and $(i+1)$ th VSLS, respectively, and $v_{k}$ is the maximum speed limit under special conditions such as heavy snow, heavy fog, and other extreme weather. At the same time, the speed limits of VSLS in this paper should be an integer between 20 and 100, and the speed difference of each adjacent VSLS should be no more than $20 \mathrm{~km} / \mathrm{h}$ [27].

\subsubsection{Objective Function 2: Maximizing Information Benefit.} In this section, we first introduce the information benefit; several literatures have introduced the information benefit (e.g., Ni and Liu, 2003 [18]; Niu et al., 2010 [28]; Yuan, 2006 [29]); in these studies, the information benefit is an quantitative indicator which combined the VMS influence index, attenuation coefficient, traffic volume, and $0-1$ variables $\left(z_{r}=0,1\right)$. These models aim at variable message signs (VMS), while we can refer to them and apply them to the deployments of VSLS. In order to study conveniently, the VSLS control zone is divided into several small VSLS control areas shown as Figure 5.

The first maximum information benefit model (i.e., the traditional model) was proposed by $\mathrm{Ni}$ and Liu to explore the deployment of VMS (in this paper it is also applied to VSLS), the model shown as follows:

$$
\max \quad F=\sum_{i=1}^{n} f_{r i} \times\left(\sum_{i=1}^{n} z_{r i} \times\left(\sum_{i=1}^{n} q_{r i} e_{r}^{i}\right)\right) \quad z_{r}=0,1,
$$

where $F$ is information benefit, $i$ are numbers of VMS/VSLS, $r$ is route path, and $f_{r i}$ is traffic volume of the $i$ th control area. $q_{r i}$ is VMS/VSLS influence index of $i$ th control area, and it could be described as incident frequency of the $i$ th control area; $q_{r i}$ should be within $[0,1] . e_{r}^{i}$ is attenuation coefficient of VMS/VSLS and $e_{r}^{i}=b^{n}$, where $b \in[0,1] ; n$ is the quantity of road from the current VMS/VSLS location to the incident occurred site. $z_{r}=0,1$ indicates whether VMS/VSLS had been set up; if they are set up, $z_{r}=1$; otherwise, $z_{r}=0$.
Then the principle of the maximum information benefit model is as follows.

At freeway work zones, drivers can pay more attention to speed limit information from the effective deployments of VSLS. In other words, drivers can obtain more information benefits from the reasonable setting of VSLS. Thus we use the idea of "maximum information benefit" to study the VSLS locations; the largest information benefits in the objective function obviously correspond to the best appropriate locations of VSLS.

Now the improved maximum information benefit model is introduced, in which the main improvements influence index and attenuation coefficient. Firstly, in Section 2.3.1, we studied the impact of accident rate on safety. So we believe that the comprehensive accident rate can better reflect the influence of VSLS than the traditional VSLS influence index $q_{r i}$; then the comprehensive accident rate $\left(C_{123}\right)$ is used to replace the traditional influence index $q_{r i}$ and the improved influence index shown as follows:

$$
q_{r i}^{\prime}=C_{123}=\frac{\left(\beta_{1} C_{1}\left(V_{i}\right)+\beta_{2} C_{2}\left(\Delta V_{i}\right)\right)}{n}+\beta_{3} C_{3}(\delta),
$$

where $C_{123}, \beta_{1}, \beta_{2}, \beta_{3}, C_{1}\left(V_{i}\right), C_{2}\left(\Delta V_{i}\right), C_{3}(\delta)$, and $n$ are the same as those in (4) and (5).

Secondly, we improved the attenuation coefficient. In traditional model, the attenuation coefficient only depends on the quantity of road from the current VSLS location to the incident site. Actually it is also affected by travel time of each VSLS control area which has been proposed in some papers. Hence, the improved attenuation coefficient should be

$$
e_{r}^{\prime i}=b^{n} \times \bar{t}_{r i}
$$

where $n$ and $b$ are the same as those in the traditional model; $\bar{t}_{r i}$ is average travel time of the $i$ th VSLS control area. $\bar{t}_{r i}=$ $l_{i} / v_{i}$, where $l_{i}$ is the length of the $i$ th VSLS control area and $v_{i}$ is the speed of the $i$ th VSLS.

Finally, the improved maximum information benefit model can be expressed as follows:

$$
\begin{aligned}
\max \quad F & =\sum_{i=1}^{n} f_{r i} \times\left(\sum_{i=1}^{n} z_{r i} \times\left(\sum_{i=1}^{n} q_{r i}^{\prime} e_{r}^{\prime i}\right)\right) \\
& =\sum_{i=1}^{n} f_{r i} \times \sum_{i=1}^{n} z_{r i} \times\left(\sum_{i=1}^{n}\left(\frac{\left(\beta_{1} C_{1}\left(V_{i}\right)+\beta_{2} C_{2}\left(\Delta V_{i}\right)\right)}{n}+\beta_{3} C_{3}(\delta)\right)\left(b^{n} \times \bar{t}_{r i}\right)\right) .
\end{aligned}
$$

2.3.3. Bilevel Programming Model. The bilevel programming model in this paper includes the following two objects: the first object is to optimize the speed limits and numbers of
VSLS, and the second object is to optimize the locations of VSLS. The bilevel programming model is

$$
\begin{aligned}
& J_{1}=\operatorname{Min} \frac{\sum_{i=1}^{n} \frac{\left(\beta_{1} C_{1}\left(v_{i}\right)+\beta_{2} C_{2}\left(\Delta v_{i}\right)\right)}{n}+\beta_{3} C_{3}(\delta),}{J_{2}=\operatorname{Max} \sum_{i=1}^{n} f_{r i} \times \sum_{i=1}^{n} z_{r i} \times\left(\sum_{i=1}^{n}\left(\frac{\left(\beta_{1} C_{1}\left(V_{i}\right)+\beta_{2} C_{2}\left(\Delta V_{i}\right)\right)}{n}+\beta_{3} C_{3}(\delta)\right)\left(b^{n} \times \bar{t}_{r i}\right)\right),}
\end{aligned}
$$




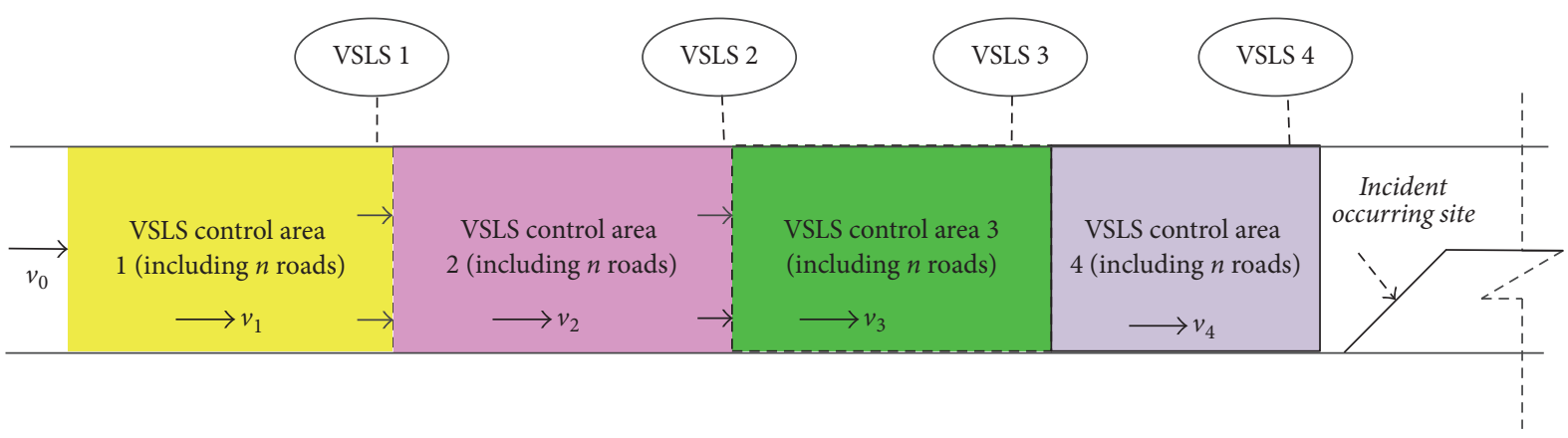

FIGURE 5: The division of VSLS control zone.

$$
\begin{aligned}
\text { s.t. } & v_{i}=\{20,30,40,50,60,70,80,90,100\} \\
v_{i} & \leq v_{k}, \\
v_{i} & -v_{i+1} \leq 20 \\
z_{r} & =0,1 \\
\bar{t}_{r i} & =\frac{l_{i}}{v_{i}}
\end{aligned}
$$

where $J_{1}$ is the first objective function, $J_{2}$ is the second objective function, and other variables are the same as the independent minimum comprehensive accident rate model and improved maximum information benefit model.

\section{Case Study}

In this section, the corresponding algorithms are performed with the experiment. The two objective functions of the bilevel programming model are solved by different algorithms. The first objective function is solved by exhaustive algorithm, and the second objective function is solved by genetic algorithm.

3.1. Objective Function 1 Optimization. Generally, the more the VSLS, the better the control effects. However, setting too many VSLS can not only waste resources but also lose drivers' trust. Moreover, it can lead to other safety problems because of the frequent distractions. Therefore, the VSLS setting numbers of freeway work zones should be moderate. And the cost factor should be considered.

An exhaustive method is used to solve this objective function. Firstly, we assume the initial speed $v_{0}$ to be normal freeway speed, that is, $120 \mathrm{~km} / \mathrm{h}$. If these VSLS can decrease vehicle speed gradually from the initial speed $(120 \mathrm{~km} / \mathrm{h})$ to a safe level, then they can also ensure safety if $v_{0}$ is less than $120 \mathrm{~km} / \mathrm{h}$. So the exhaustive algorithm is implemented by MATLAB, and the simulation results are shown in Table 1.

As can be seen from Table 1, the minimum comprehensive accident rates are reduced gradually with the increasing of VSLS numbers, and they decrease slowly when VSLS number is larger than 4 where the corresponding accident rate is 0.562 , which decreased by about $75 \%$ when compared with that of VSLS number $=1$ (the accident rate is 2.247). Hence, the accident rate is considered to have been reduced to the safe level when VSLS number is $\geq 4$; thus the VSLS number should be $4(n=4)$ after taking account of the cost factor and the fact that too many VSLS will distract drivers' attention. This number is derived empirically and it is useful for the future research. The reduction trend of the minimum comprehensive accident rate is shown in Figure 6.

However, in reality, vehicles could slow down in advance due to the warning sign, so $v_{0}$ could not be $120 \mathrm{~km} / \mathrm{h}$. The existing studies presume that the vehicles speed could be close to $60 \mathrm{~km} / \mathrm{h}$ when they approach the work zone. Therefore, in this paper we choose $v_{0}$ to be $60 \mathrm{~km} / \mathrm{h}$; thus under this condition, vehicle speed is gradually decreased by these VSLS when drivers travel through the work zone. Another simulation under the known conditions of $n=4$ and $v_{0}=60$ is performed, and the result is shown in Table 2.

As shown in Table 2, the best control speed limits are $50 \mathrm{~km} / \mathrm{h}, 40 \mathrm{~km} / \mathrm{h}, 30 \mathrm{~km} / \mathrm{h}$, and $20 \mathrm{~km} / \mathrm{h}$. So the VSLS numbers $(n=4)$ and the corresponding speed limits $\left(V_{1}=\right.$ $50 \mathrm{~km} / \mathrm{h}, V_{2}=40 \mathrm{~km} / \mathrm{h}, V_{3}=30 \mathrm{~km} / \mathrm{h}$, and $V_{4}=20 \mathrm{~km} / \mathrm{h}$ ) have been obtained in this section.

Now we consider that the speed distribution at freeway work zones is from $50 \mathrm{~km} / \mathrm{h}$ to $20 \mathrm{~km} / \mathrm{h}$. The speed limits $V_{1}=$ $50 \mathrm{~km} / \mathrm{h}, V_{2}=40 \mathrm{~km} / \mathrm{h}, V_{3}=30 \mathrm{~km} / \mathrm{h}$, and $V_{4}=20 \mathrm{~km} / \mathrm{h}$ represent the actual vehicle speed during the transition from the end of free flow to synchronized flow and then to jam. Under these conditions, the traffic flow is simulated to illustrate the empirical nucleation nature of traffic breakdown at freeway work zones. To simplify the analysis, we choose flow rate per three minutes as the simulation object, and total simulation time is 90 minutes; total simulation distance is $16 \mathrm{~km}$. Simulation results are shown in Figures 7 and 8 . Figure 7 demonstrates the relationship between vehicle density and flow rate, which comply with "three-phase theory." 
TABLE 1: Result of minimum comprehensive accident rate model.

\begin{tabular}{lrr}
\hline$n /$ VSLS number & $\begin{array}{c}C_{123}(\text { minimum comprehensive accident } \\
\text { rate }) /\left(10^{-7} \cdot \mathrm{pcu}^{-1} \cdot \mathrm{km}^{-1}\right)\end{array}$ & $V_{i}($ speed limit value $) /\left(\mathrm{km} \cdot \mathrm{h}^{-1}\right)$ \\
\hline 1 & 2.247 & 100 \\
2 & 1.124 & 100,90 \\
3 & 0.749 & $100,90,80$ \\
4 & 0.562 & $100,90,80,70$ \\
5 & 0.450 & $100,90,80,70,60$ \\
6 & 0.375 & $100,90,80,70,60,50$ \\
7 & 0.321 & $100,90,80,70,60,50,40$ \\
& 0.281 & $100,90,80,70,60,50,40,30$ \\
\hline
\end{tabular}

TABLE 2: Actual speed limits of the four VSLS.

\begin{tabular}{lccc}
\hline$V_{1}$ & $V_{2}$ & $V_{3}$ & $V_{4}$ \\
\hline $50 \mathrm{~km} / \mathrm{h}$ & $40 \mathrm{~km} / \mathrm{h}$ & $30 \mathrm{~km} / \mathrm{h}$ & $20 \mathrm{~km} / \mathrm{h}$ \\
\hline
\end{tabular}

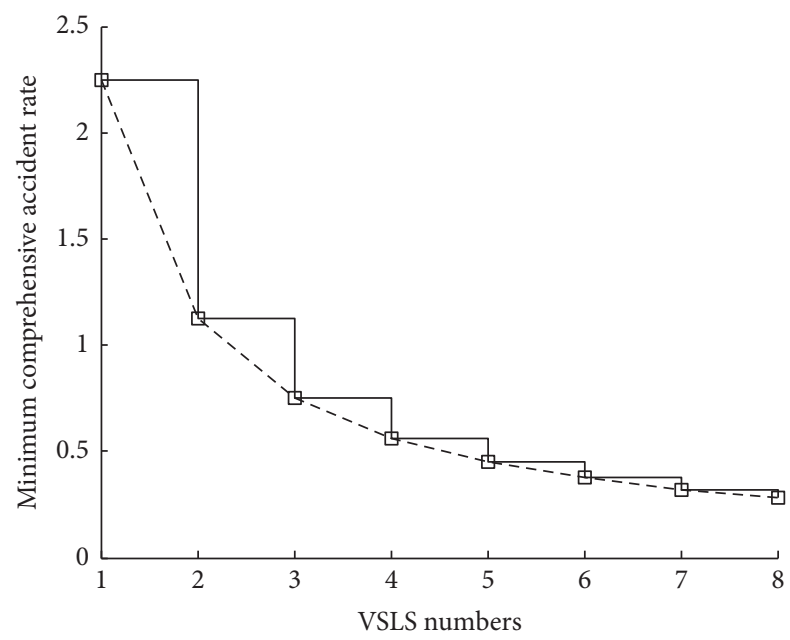

FIGURE 6: Reduction trend of the minimum comprehensive accident rate.

Figure 8 is the temporal-spatial distribution of traffic flow, in which the traffic breakdown phenomenon is clearly shown.

3.2. Objective Function 2 Optimization. In this section, genetic algorithm is applied to solve the second objective function. This is because the second objective function can be treated as a mathematical optimization problem, and the major optimal objects are VSLS locations. In the design of genetic algorithm, fitness represents the objective function value (i.e., the information benefit), so if fitness is bigger, information benefit is also bigger; then the location of VSLS is better. Genetic algorithm includes the following steps.

(1) Code Design. In order to speed up the development, we choose float-point computation instead of fixed point computation to implement our algorithm. Firstly, we define the chromosome length as $L$, which means that there are $L$ alternative locations for the VSLS. Decoding process is as follows: taking the first four biggest numbers of all floatingpoints and setting their locations with 1 , it indicates that the

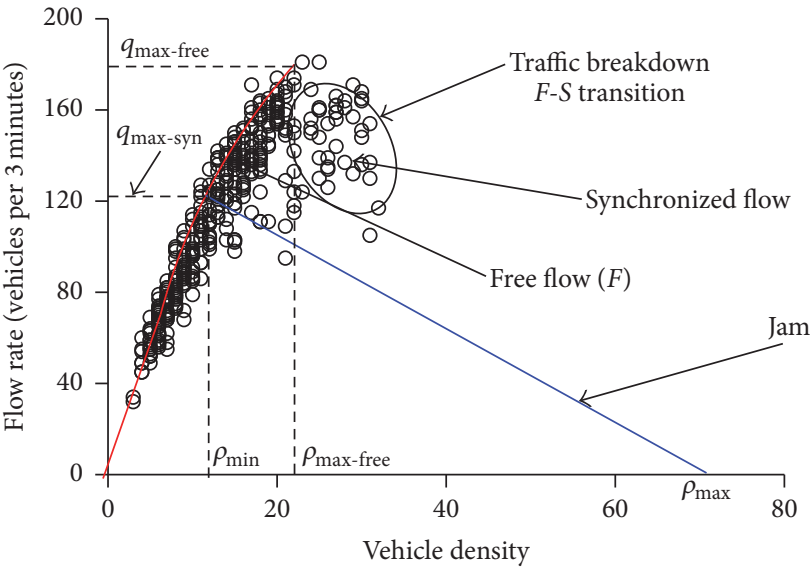

FIGURE 7: Relationship between flow rate and vehicle density.

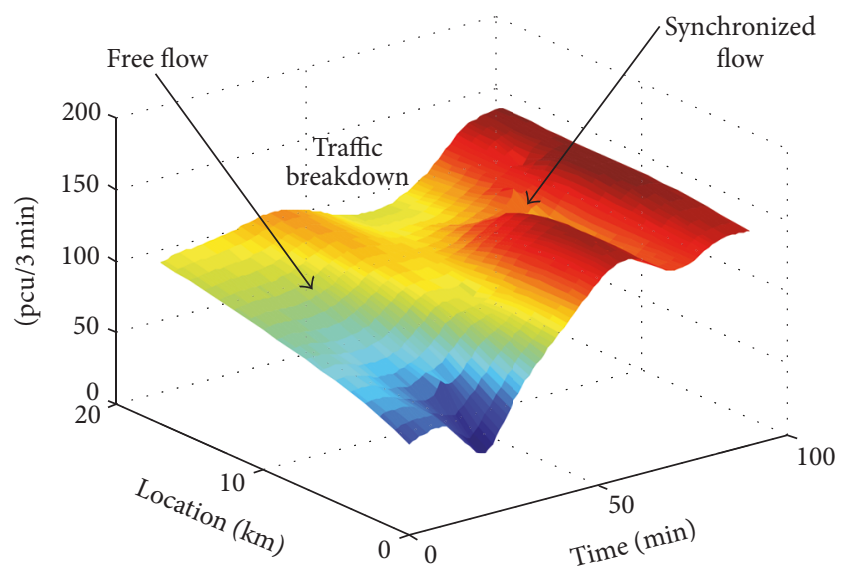

FIgURE 8: Temporal-spatial distribution of traffic flow at freeway work zones.

locations are selected as the actual VSLS locations and the nonselected locations are set with 0 . For instance, a decoded chromosome result is [1000100110] which means that the locations $1,5,8$, and 9 are selected as the VSLS setting locations.

(2) Fitness Function Design. Because the goal is to obtain the maximum value of objective function (i.e., the information 


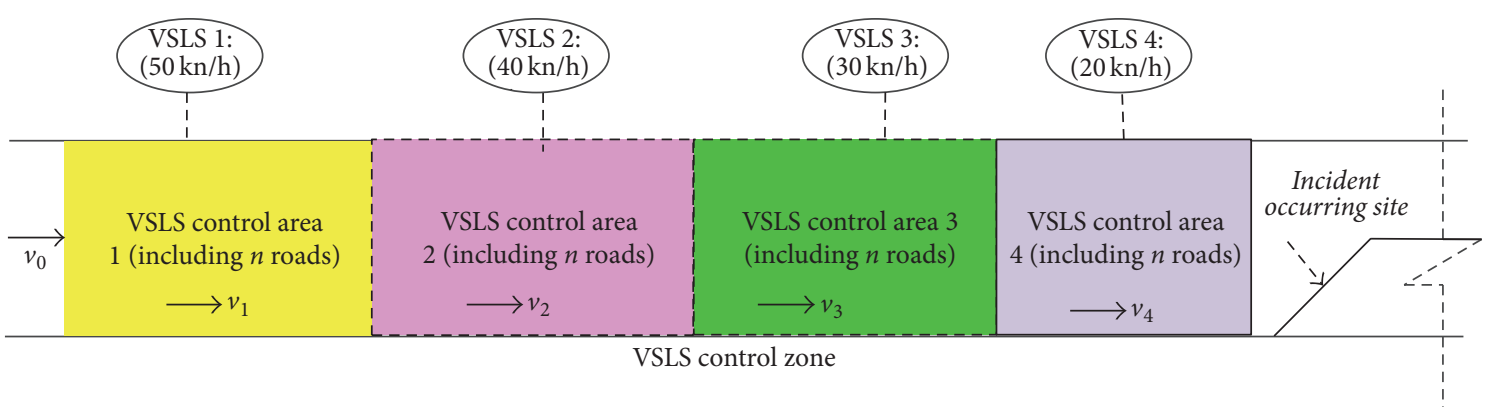

FIGURE 9: VSLS distribution of each control area.

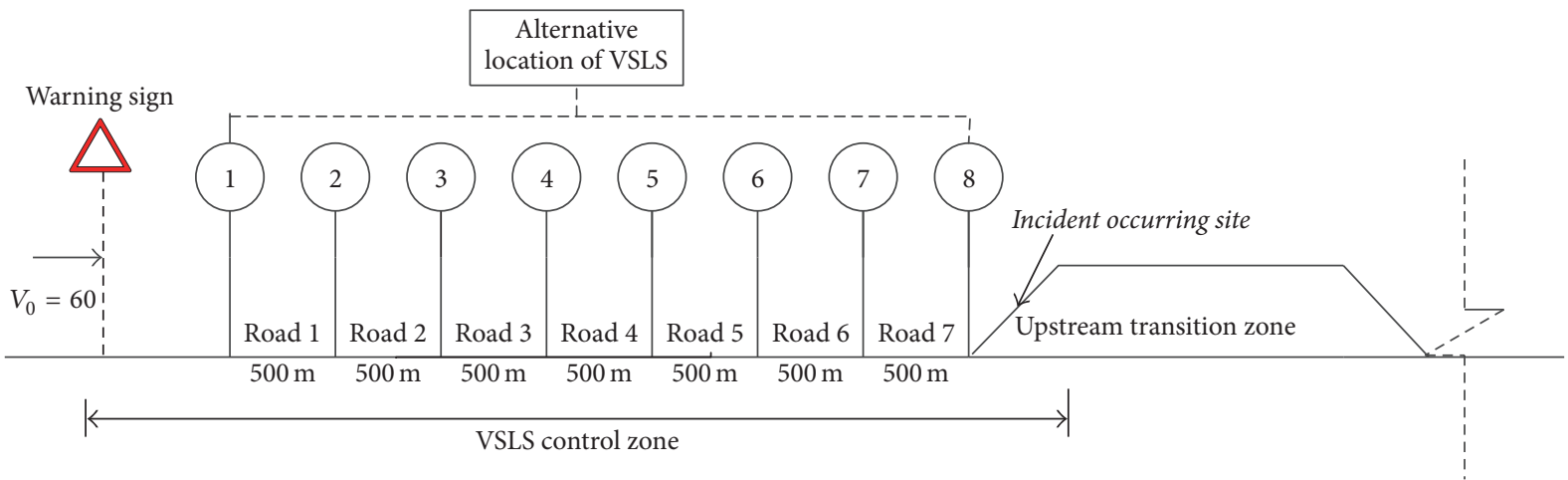

FIGURE 10: Simulation network of freeway work zone.

benefit), we treat the objective function as fitness. Then the best locations must be the roots to the biggest fitness.

(3) Population Initialization Design. In this paper, the population is initialized randomly because of its fast convergence.

(4) Genetic Operation. Genetic operation consists of three steps: selection, crossover, and variation. A roulette selection process is used to implement the select operation. Then a two-point crossover strategy is employed to implement the crossover operation. We first chose the intersection point at a certain probability and then exchange a set of chromosomal genes. At last, this process will produce a set of results.

From Section 3.1, the numbers and corresponding speed limits have been optimized, that is, $n=4, V_{1}=50 \mathrm{~km} / \mathrm{h}$, $V_{2}=40 \mathrm{~km} / \mathrm{h}, V_{3}=30 \mathrm{~km} / \mathrm{h}$, and $V_{4}=20 \mathrm{~km} / \mathrm{h}$. Then the VSLS control zone is shown as in Figure 9.

A simulated road network of the freeway work zone is built to show the deployments of the four VSLS (see Figure 10). Related parameters of the simulated road network of the freeway work zone are set as follows:

(1) 8 locations are chosen as the alternative locations of VSLS, because if they are beyond 8 , the calculation is very complicated, while if they are too small, the convergence will be too fast, so after many trials, the alternative locations are 8.

(2) The assumption is that an incident happens at the upstream transition zone at a certain time, because only in this condition would the study be meaningful.
(3) Each road length is $500 \mathrm{~m}$ with a traffic volume of $500 \mathrm{pcu} / \mathrm{h}$ when the incident happens (this hypothesis is convenient for our simulation with VISSIM).

Now we need to set four VSLS to get more information benefits, and under this condition, the traffic situation and the secondary accident rate could be decreased. The speed limits of the four VSLS are $V_{1}=50 \mathrm{~km} / \mathrm{h}, V_{2}=40 \mathrm{~km} / \mathrm{h}$, $V_{3}=30 \mathrm{~km} / \mathrm{h}$, and $V_{4}=20 \mathrm{~km} / \mathrm{h}$. Following this, we search for the best VSLS locations by solving the second objective function with the genetic algorithm; result shows that the largest benefit information is $2.35 \times 10^{5}$, which corresponds to the locations $1,2,3$, and 8 .

\section{Model Comparison and Simulation Evaluation}

4.1. Model Comparison. In this section, four models are used for comparison; apart from the improved information benefit model (the second objective function of the bilevel programming model) and traditional information benefit model that $\mathrm{Ni}$ and Liu have proposed, another two models are proposed by this paper so as to make a more comprehensive contrast. In this paper, model 4 (traditional model which is the existing model) is the criterion for the comparison, and the other three models are all improved on the basis of model 4 .

The four models are expressed as follows:

(1) Model 1: improved maximum information benefit model, that is, the second objective function of the bilevel programming model 


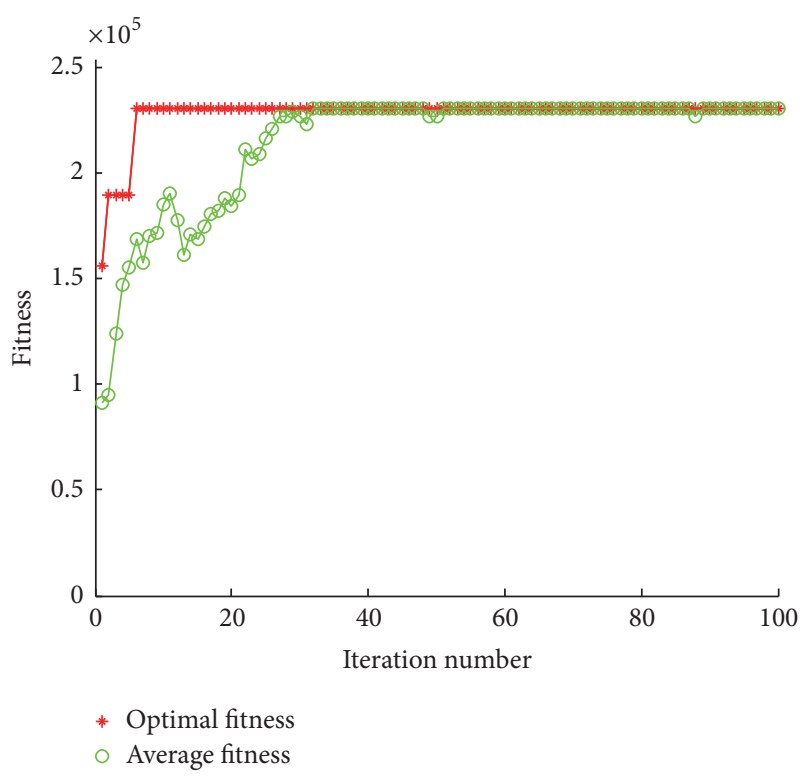

(a) Model 1

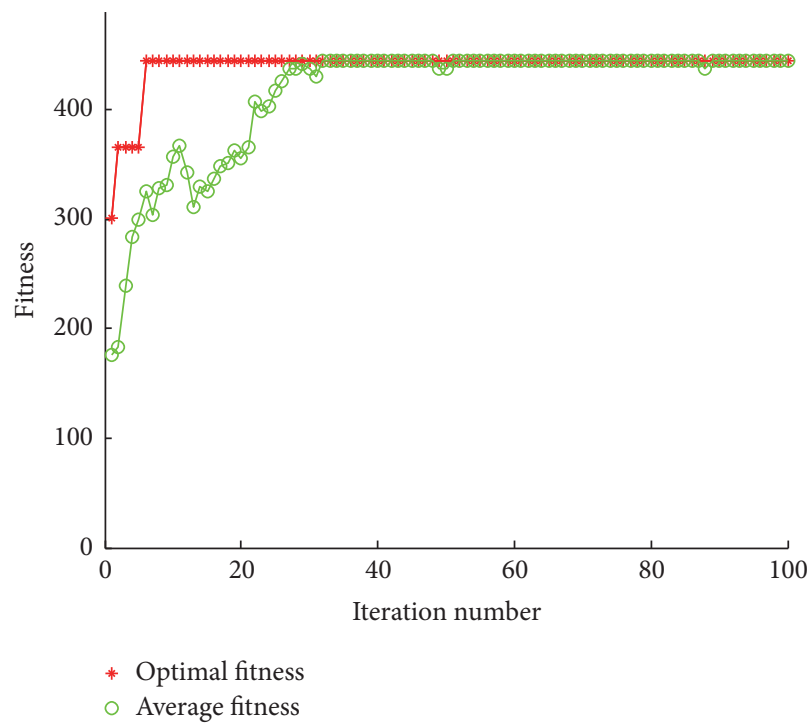

(c) Model 3

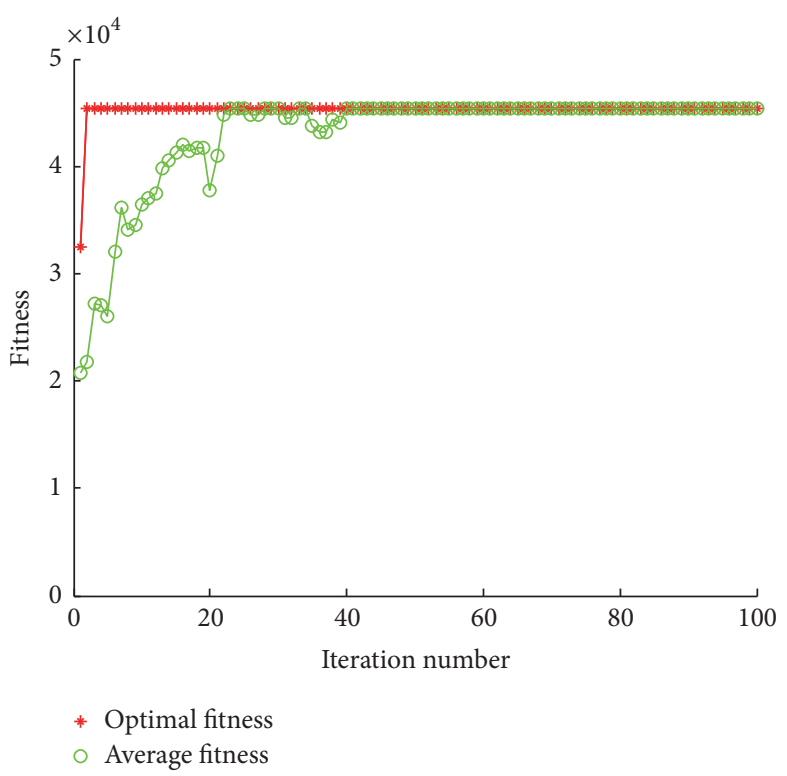

(b) Model 2

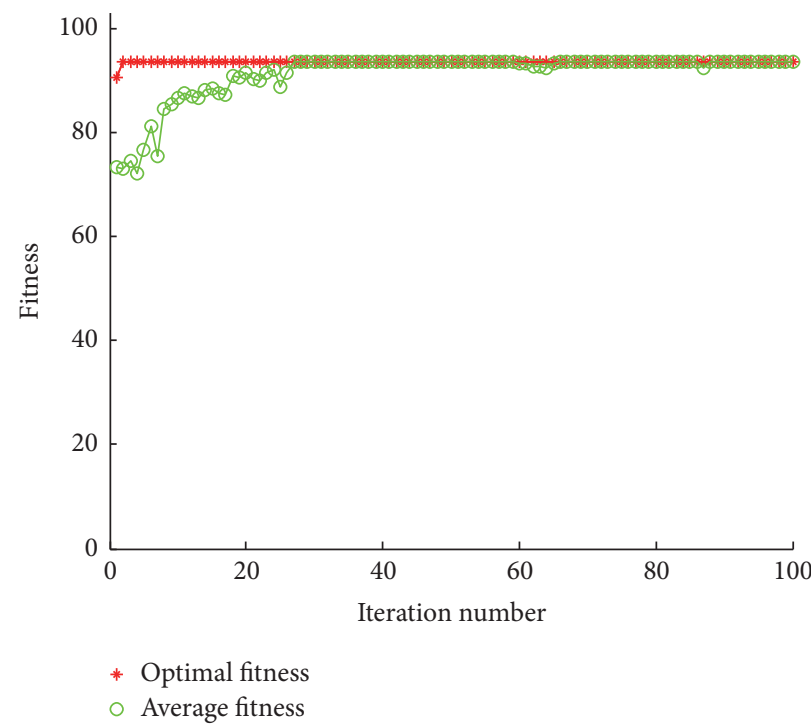

(d) Model 4

FIGURE 11: Results comparison of the four models.

(2) Model 2: maximum information benefit model where the attenuation coefficient is constant (it is the same as traditional information benefit model) and the influence index is the same as model 1

(3) Model 3: maximum information benefit model where the influence index is constant (it is the same as traditional information benefit model) and the attenuation coefficient is the same as model 1

(4) Model 4: traditional information benefit model proposed by $\mathrm{Ni}$ and Liu.

Genetic algorithm is used to solve these models, and the results are [11100001], [11110000], [11100001], and
[00011110], respectively, and the corresponding largest information benefits of the four models are $2.35 \times 10^{5}, 4.5 \times 10^{4}, 4.5$ $\times 10^{2}$, and 93 , respectively. Genetic algorithm iteration curves of the four models are seen in Figure 11.

From the largest information benefits of four models, it can be seen that the best deployment of VSLS comes from model 1 , followed by model 2 , model 3 , and model 4 . Their deployments are in locations $1,2,3$, and $8 ; 1,2,3$, and $4 ; 1,2$, 3 , and $8 ; 4,5,6$, and 7 , respectively. Figure 11 shows that the largest information benefit of model 1 increased by $80.85 \%$ compared with model 2 , and it is so many times larger than that of model 3 and model 4 . Hence, the improved maximum information benefit model (model 1) outperforms the other three models. In addition, it can be speculated from Figures 


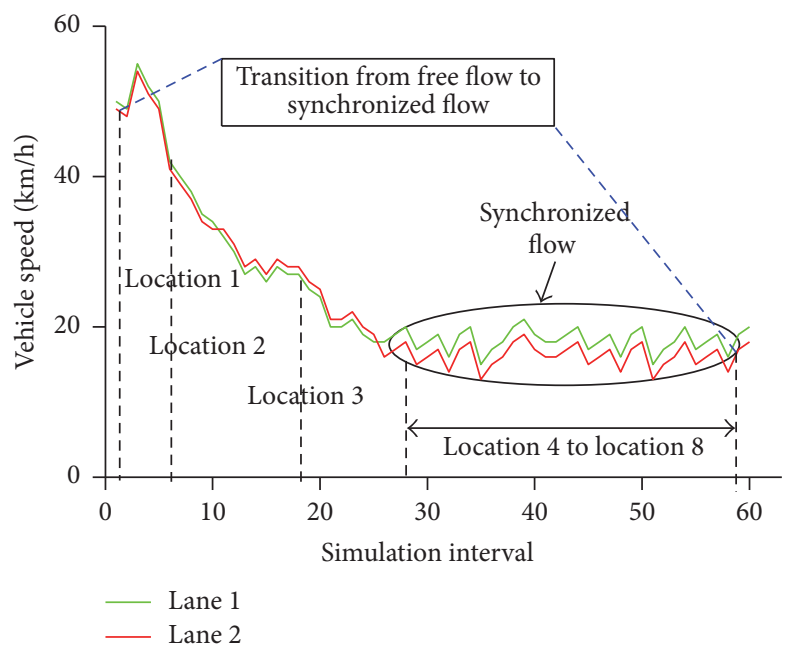

(a) Speed distribution of locations 1, 2, 3, and 4

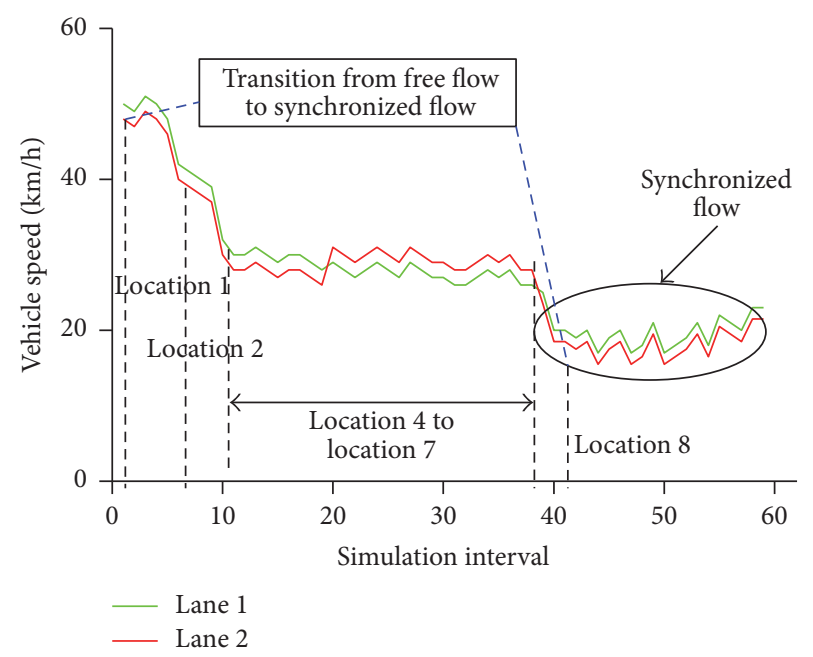

(b) Speed distribution of locations 1, 2, 3, and 8

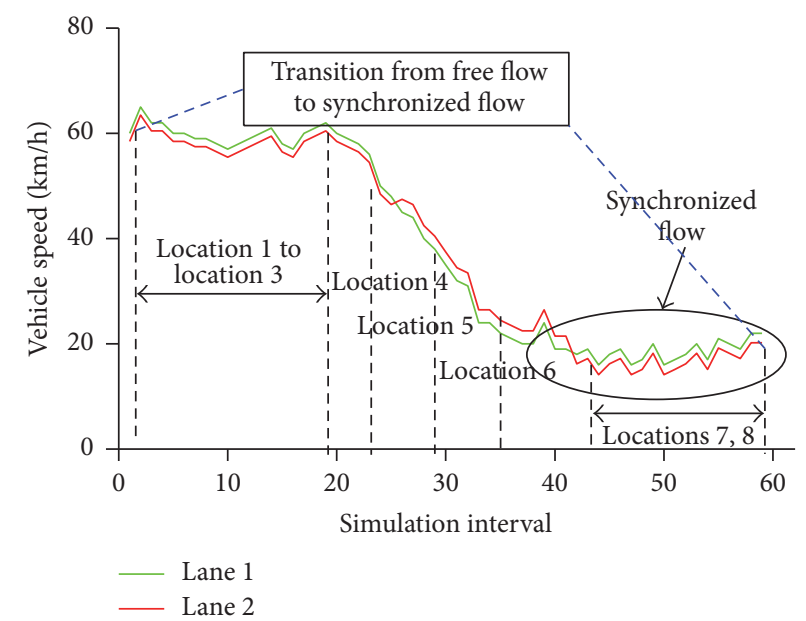

(c) Speed distribution of locations 4, 5, 6, and 7

Figure 12: Speed distribution of different deployments.

11(b) and 11(c) that the influence index is the most important influencing factor in the maximum information benefit model.

4.2. Simulation Evaluation. In terms of different deployments of VSLS and their corresponding speed limits at freeway work zones, the situation of traffic flow of each deployment (i.e., locations 1, 2, 3, and 8; locations 1, 2, 3, and 4; locations 4, 5, 6, and 7) is simulated, respectively, by VISSIM. Two simulations are performed; the first is to show if the relative deployments of VSLS at freeway work zones are consistent with the actual traffic situation of freeway work zones. Because the velocity distribution of each deployment (i.e., locations 1, 2, 3, and 4; locations 1, 2, 3, and 8; and locations 4, 5, 6, and 7) is $50 \mathrm{~km} / \mathrm{h}, 40 \mathrm{~km} / \mathrm{h}, 30 \mathrm{~km} / \mathrm{h}$, and $20 \mathrm{~km} / \mathrm{h}$, we use this velocity distribution to simulate the actual traffic flow. In Figures 12(a) and $12(\mathrm{~b})$, the initial velocities in location 1 are all $50 \mathrm{~km} / \mathrm{h}$ and the end speeds are all stable $(20 \mathrm{~km} / \mathrm{h})$; this state is called synchronized flow state. In Figure 12(c) the initial velocity of locations 1,2 , and 3 is about $60 \mathrm{~km} / \mathrm{h}$, and it will decrease to $50 \mathrm{~km} / \mathrm{h}, 40 \mathrm{~km} / \mathrm{h}, 30 \mathrm{~km} / \mathrm{h}$, and $20 \mathrm{~km} / \mathrm{h}$ in locations 4 ,
5,6 , and 7 , and the stable speed $20 \mathrm{~km} / \mathrm{h}$ will be kept from location 7 to downstream transition zone, whose state is the synchronized flow state. It should be noted that the accident happened near the upstream transition zone (see Figure 10), and near this area the traffic breakdown will happen at a certain time. So we think that before the synchronized flow comes into being, the state at freeway work zones may be the transition from free flow to synchronized flow which are shown in Figures 12(a), 12(b), and 12(c).

The three different deployments of VSLS in Figure 12 present the actual traffic characteristics of the freeway work zone. Vehicles speed has been reduced to $60 \mathrm{~km} / \mathrm{h}$ from free flow $(120 \mathrm{~km} / \mathrm{h})$ because of the warning sign, and now it can continue to reduce by the consecutive VSLS until it keeps in a stable state (the speed is nearly $20 \mathrm{~km} / \mathrm{h}$ ). This change corresponds to the transition from free flow to synchronized flow which may illustrate the empirical nucleation nature of traffic breakdown at freeway work zones.

The second simulation is to evaluate the relevant parameters (e.g., average queue length, travel time, total stop frequency, and total delay) of each model to show the superiority 

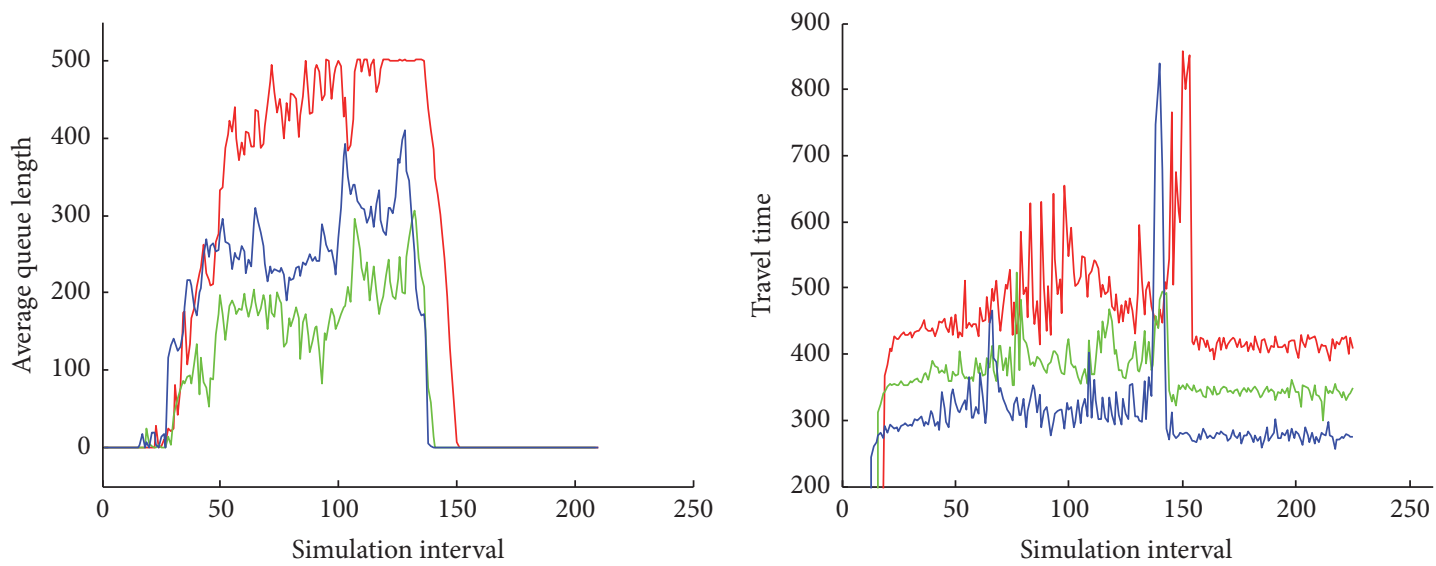

Location $1,2,3$, and 4
- Location $1,2,3$, and 8
Location $4,5,6$, and 7

(a) Average queue length of different deployments

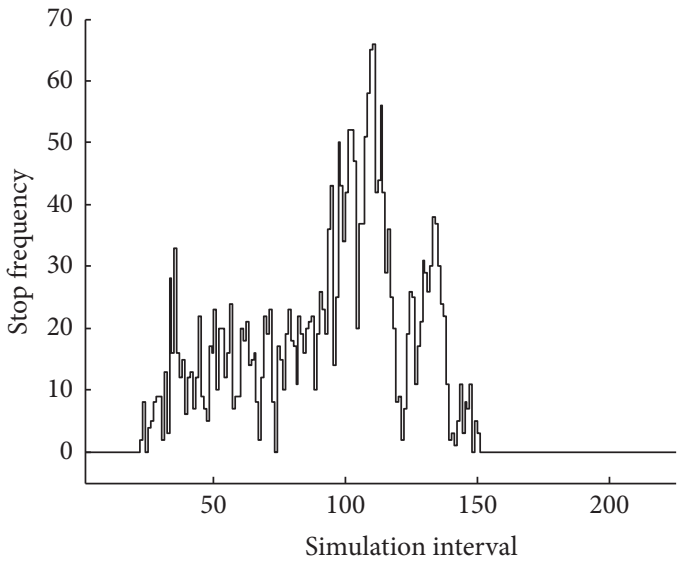

(c) Stop frequency of locations 1, 2, 3, and 4

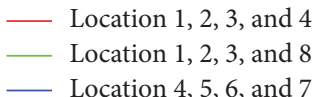

(b) Travel time of different deployments

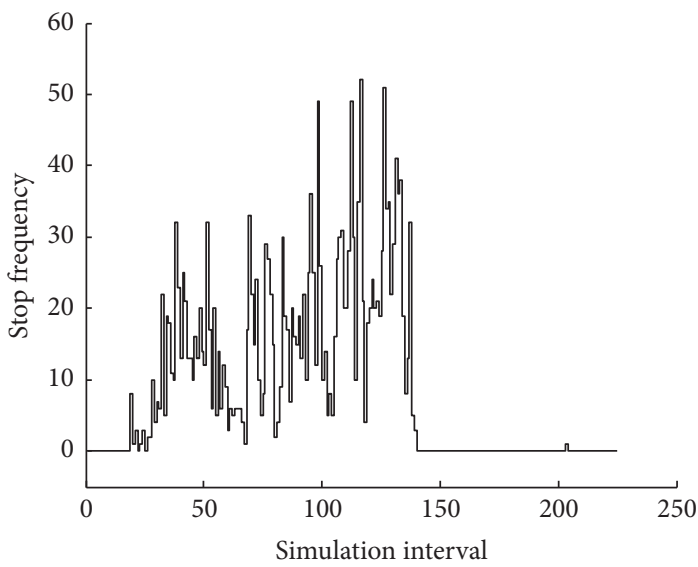

(d) Stop frequency of locations 1, 2, 3, and 8
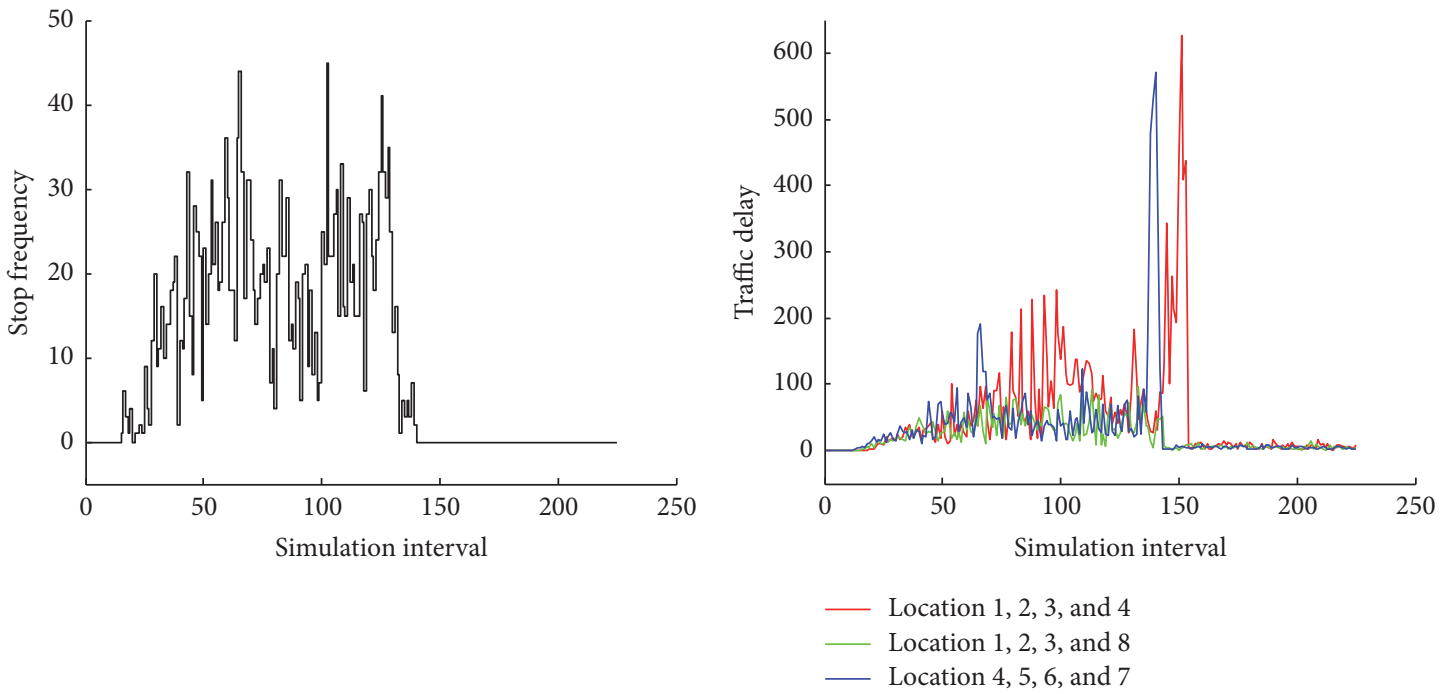

(e) Stop frequency of locations 4, 5, 6, and 7

(f) Traffic delay of different deployments

FIGURE 13: Evaluation results of different deployments. 
of the model proposed in this paper (model 1, improved maximum information benefit model). Total simulation time is 4500 seconds and every 20 seconds a count is made. Total length of simulation road is the same as the road in Figure 10, total traffic volume is $3000 \mathrm{pcu} / \mathrm{h}$, and the simulation speed of the corresponding VSLS is $50 \mathrm{~km} / \mathrm{h}, 40 \mathrm{~km} / \mathrm{h}, 30 \mathrm{~km} / \mathrm{h}$, and $20 \mathrm{~km} / \mathrm{h}$. Evaluation results of different deployments of VSLS are shown in Figure 13.

Figures 13(a) and 13(f) indicate that the average queue length and total delay of locations $1,2,3$, and 8 are less than the other two deployments. Total delay of locations 1 , 2, 3, and 8 is $92 \mathrm{~s}$, which decreased by $41.02 \%$ and $19.51 \%$, respectively, compared with locations 1, 2, 3, and 4 (total delay is $156 \mathrm{~s}$ ) and locations $4,5,6$, and 7 (total delay is $114.3 \mathrm{~s}$ ). Figure 13(b) shows that the travel time of locations 1, 2, 3, and 8 is not the shortest, which suggest that the travel time is not fully decreased sometimes through the effective VSLS control. Figures 13(c), 13(d), and 13(e) illustrate that there is little difference of the stop frequency distribution between the three deployments; that is, the stop phenomenon all appeared before the 50th simulation interval and disappeared after the 150th simulation interval. However, the total stop frequency of the three deployments is different; that is, the total stop frequency of locations $1,2,3$, and 8 is 2050, which decreased by $24.46 \%$ and $5.08 \%$, respectively, compared with locations $1,2,3$, and 4 (total stop frequency is 2552 ) and locations 4,5 , 6 , and 7 (total stop frequency is 2167).

All of the above indicate that the effective VSLS control can not only be consistent with the empirical nucleation nature of traffic breakdown but also reduce average queue length, total delay, and total stop frequency.

\section{Conclusions}

A bilevel programming model is established to study the VSLS control of freeway work zones. The first object of the bilevel programming model is to minimize comprehensive accident rate, where VSLS numbers and the corresponding speed limits are determined. The second object is to maximize the information benefit, where the best deployment of VSLS is obtained. Case study shows the following results:

(1) The best appropriate number of VSLS at the freeway work zone of the simulated road network is 4 and the corresponding speeds are $50 \mathrm{~km} / \mathrm{h}, 40 \mathrm{~km} / \mathrm{h}, 30 \mathrm{~km} / \mathrm{h}$, and $20 \mathrm{~km} / \mathrm{h}$, respectively.

(2) The best deployments of VSLS are locations 1, 2, 3, and 8 at the freeway work zone of the simulated road network.

Results of our method (the two objective functions) show that the traffic flow is consistent with "three-phase theory" at the known conditions; that is, $V_{1}=50 \mathrm{~km} / \mathrm{h}, V_{2}=40 \mathrm{~km} / \mathrm{h}$, $V_{3}=30 \mathrm{~km} / \mathrm{h}$, and $V_{4}=20 \mathrm{~km} / \mathrm{h}$, VSLS deployment is in locations $1,2,3$, and 8 , and they also show the traffic breakdown phenomenon which may be consistent with the empirical nucleation nature in some degree. Meanwhile, model comparison and simulation evaluation demonstrate that the model (model 1) proposed in this paper is better than other models (models 2, 3, and 4) in enhancing the information benefit. And the efficient VSLS control (i.e., reasonable speed limits and right deployment) can decrease the average queen length, total delay, and total stop frequency of vehicles at freeway work zones.

Despite the fact that implementing effective VSLS control can reduce the comprehensive accident rate and smoothen the traffic flow of the freeway work zone, there are still several shortcomings in the study. For instance, the types of the different work zones are not fully considered, the empirical features of traffic breakdown at freeway work zones need to be further studied, and some assumptions (e.g., the initial speed $v_{0}$, the length and traffic volume of each control zone in the simulated network) are ideal. Future research needs to address the above issues.

\section{Conflicts of Interest}

The authors declare that they have no conflicts of interest.

\section{Acknowledgments}

This research has been jointly supported by National Key Technology Support Program (Grant no. 2014BAG03B03).

\section{References}

[1] W.-H. Zhang and H.-G. Xu, "Calculation model of speed-limit value for traffic accident scene section on freeway," Journal of Traffic and Transportation Engineering, vol. 11, no. 1, pp. 114-118, 2011.

[2] C. Lee, B. Hellinga, and F. Saccomanno, "Evaluation of variable speed limits to improve traffic safety," Transportation Research Part C: Emerging Technologies, vol. 14, no. 3, pp. 213-228, 2006.

[3] R. L. Bertini, S. Boice, and K. Bogenberger, "Dynamics of variable speed limit system surrounding bottleneck on German autobahn," Transportation Research Record, vol. 1978, no. 1, pp. 149-159, 2006.

[4] B. Khondaker and L. Kattan, "Variable speed limit: a microscopic analysis in a connected vehicle environment," Transportation Research Part C: Emerging Technologies, vol. 58, pp. 146-159, 2015.

[5] A. Nissan and H. N. Koutsopoulosb, "Evaluation of the impact of advisory variable speed limits on motorway capacity and level of service," Procedia-Social and Behavioral Sciences, vol. 16, no. 1, pp. 100-109, 2011.

[6] T. Mcmurtry, M. Saito, F. Asce, M. Riffkin, and S. Health, "Variable speed limits signs: effects on speed and speed variation in work zones," Transportation Research E-Circular, 2009.

[7] X.-Y. Lu, P. Varaiya, R. Horowitz, D. Su, and S. E. Shladover, "A new approach for combined freeway variable speed limits and coordinated ramp metering," in Proceedings of the 13th International IEEE Conference on Intelligent Transportation Systems (ITSC '10), pp. 491-498, IEEE, September 2010.

[8] P.-W. Lin, K.-P. Kang, and G.-L. Chang, "Exploring the effectiveness of variable speed limit controls on highway workzone operations," Journal of Intelligent Transportation Systems: Technology, Planning, and Operations, vol. 8, no. 3, pp. 155-168, 2004. 
[9] M.-h. Ma, Q.-f. Yang, S.-d. Liang, and Z.-1. Li, "Integrated variable speed limits control and ramp metering for bottleneck regions on freeway," Mathematical Problems in Engineering, vol. 2015, Article ID 313089, 17 pages, 2015.

[10] M. Abdel-Aty, R. J. Cunningham, V. V. Gayah, and L. Hsia, "Dynamic variable speed limit strategies for real-time crash risk reduction on freeways," Transportation Research Record, vol. 2078, no. 1, pp. 108-116, 2008.

[11] P. Allaby, B. Hellinga, and M. Bullock, "Variable speed limits: safety and operational impacts of a candidate control strategy for freeway applications," IEEE Transactions on Intelligent Transportation Systems, vol. 8, no. 4, pp. 671-680, 2007.

[12] M. Abdel-Aty, J. Dilmore, and A. Dhindsa, "Evaluation of variable speed limits for real-time freeway safety improvement," Accident Analysis and Prevention, vol. 38, no. 2, pp. 335-345, 2006.

[13] N. J. Fudala and M. D. Fontaine, "Work zone variable speed limit systems: effectiveness and system design issues," Highway Operations, 2010.

[14] R.-J. Yu, R.-G. Ma, H. Han, Y. Yan, and J.-L. Wang, "Determination method of speed-limit sign position in expressway work zone," Journal of Traffic \& Transportation Engineering, vol. 13, no. 5, pp. 91-98, 2013.

[15] J. Cao, D. Hu, Y. Luo, T. Z. Qiu, and Z. Ma, "Exploring the impact of a coordinated variable speed limit control on congestion distribution in freeway," Journal of Traffic and Transportation Engineering, vol. 2, no. 3, pp. 167-178, 2015.

[16] X.-L. Jia, Z.-P. Fu, J.-L. Xu, W.-H. Chen, and L.-Z. Jing, "Effectiveness test of speed-limit sign in one-way closed work zone for expressway," Journal of Traffic and Transportation Engineering, vol. 15, no. 4, pp. 93-100, 2015.

[17] Y. Pu, L. Hu, Y.-S. Jiang, J.-X. Zhu, and B. Peng, "Variable speedlimit control before expressway mainline toll station," Journal of Traffic \& Transportation Engineering, vol. 12, no. 5, pp. 120-126, 2012.

[18] F. J. Ni and Z. C. Liu, "The optimal location of variable message signs," Information \& Control, vol. 32, no. 5, pp. 395-398, 2003.

[19] B. S. Kerner, "Criticism of generally accepted fundamentals and methodologies of traffic and transportation theory: a brief review," Physica A. Statistical Mechanics and Its Applications, vol. 392, no. 21, pp. 5261-5282, 2013.

[20] B. S. Kerner, "Failure of classical traffic flow theories: stochastic highway capacity and automatic driving," Physica A. Statistical Mechanics and Its Applications, vol. 450, pp. 700-747, 2016.

[21] B. S. Kerner, "Study of freeway speed limit control based on three-phase traffic theory," Transportation Research Record, vol. 1999, no. 1, pp. 30-39, 2007.

[22] B. S. Kerner, The Physics of Traffic, Springer, Berlin, Germany, 2004.

[23] B. S. Kerner, Introduction to Modern Traffic Flow Theory and Control, Springer, Berlin, Germany, 2009.

[24] X. L. Zhao, Research on the Traffic Safety Analysis and Facilities Setting in Reconstruction and Extension Work Zone of Highway, Harbin Institute of Technology, Harbin, China, 2007.

[25] L.-D. Zhong, X.-D. Sun, Y.-S. Chen, J. Zhang, and G.-W. Zhang, "The relationships between crash rates and average speed difference between cars and large vehicles on freeway," Journal of Beijing University of Technology, vol. 33, no. 2, pp. 185188, 2007.

[26] D. J. Hou, X. R. Sun, and Y. L. He, "Relationship between speed difference and crash rate on freeway," Transport Engineering and Safety, vol. 7, no. 224, pp. 70-72, 2010.
[27] T. Zhang, C. Tang, and Y. He, "A research on the traffic safety characteristics of two-lane highway in China's mountain area," in Proceedings of the 10th International Conference of Chinese Transportation Professionals, pp. 669-677, August 2010.

[28] S. Y. Niu, H. Liu, J. G. Feng, J. G. Luo, and S. L. Li, "The optimization of the planning and positions of VMS based on fuzzy constrained conditions," Systems Engineering, vol. 28, no. 3, pp. 98-102, 2010.

[29] S. P. Yuan, Research on the Optimal Variable Messages Signs Setting Locations Considering the Influence of Traffic Guidance Information, Beijing Jiao Tong University, Beijing, China, 2006. 


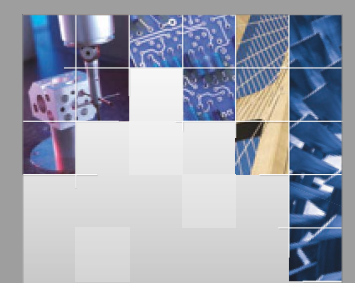

\section{Enfincering}
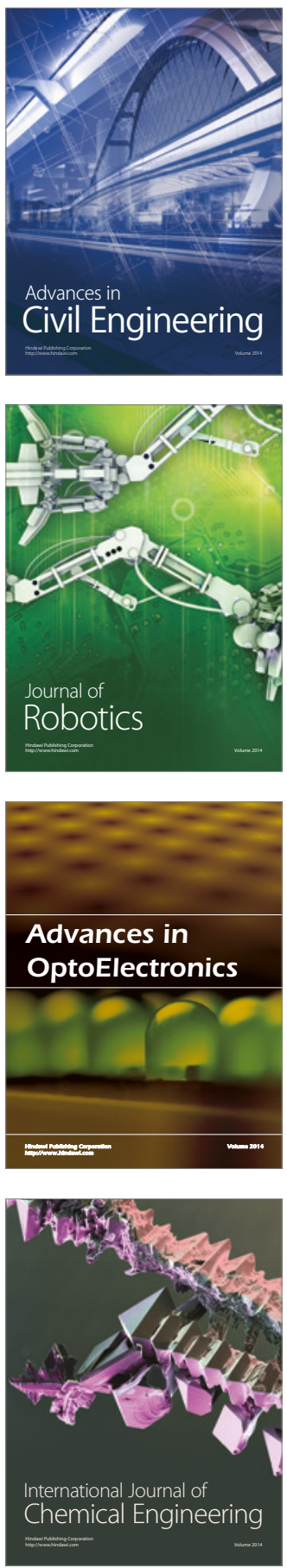

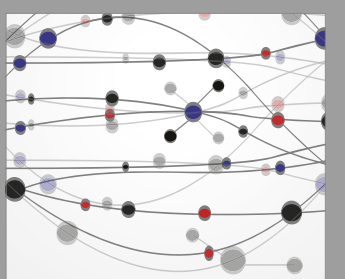

The Scientific World Journal

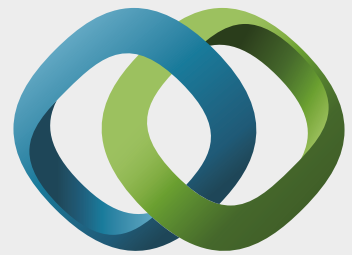

\section{Hindawi}

Submit your manuscripts at

https://www.hindawi.com
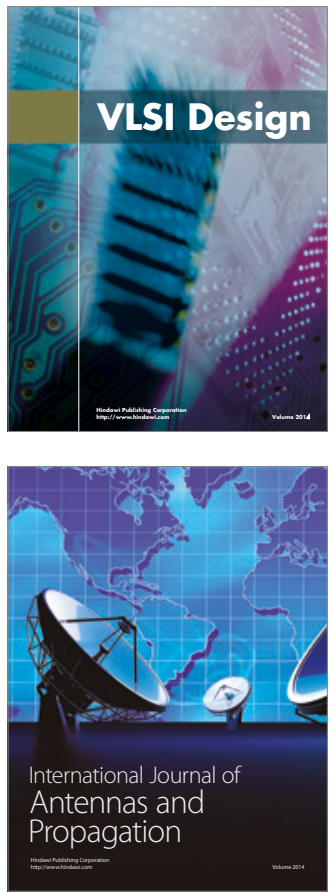

\section{Rotating}

Machinery
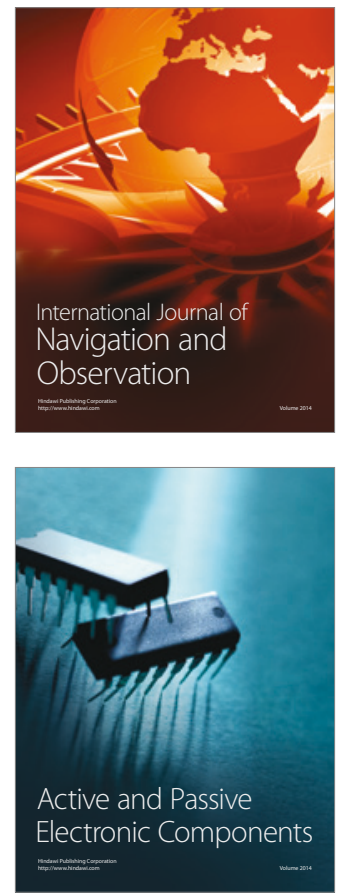
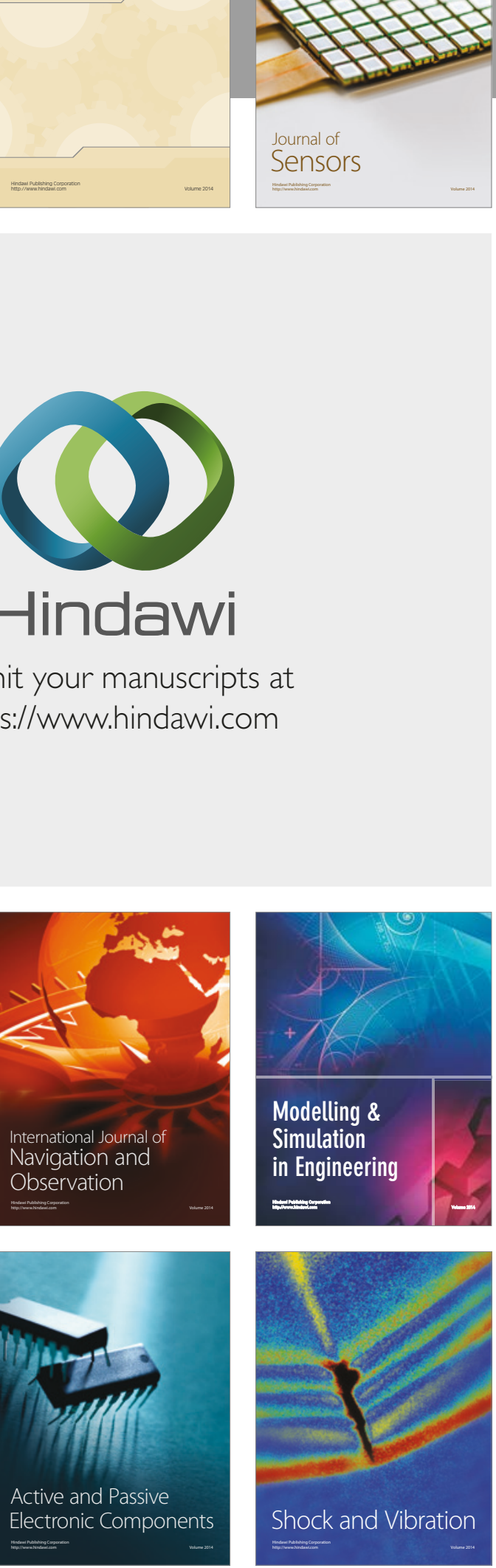
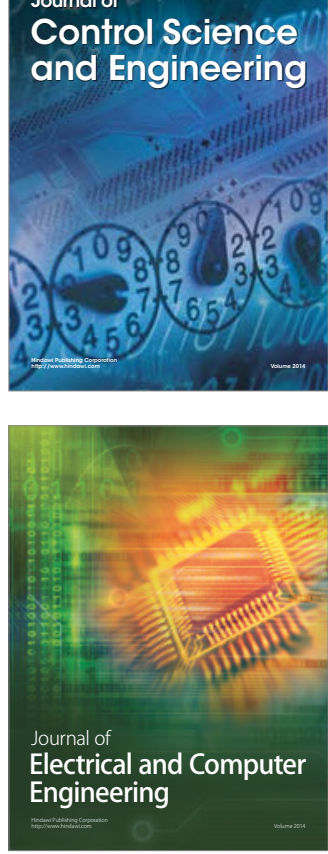

Distributed

Journal of

Control Science

and Engineering
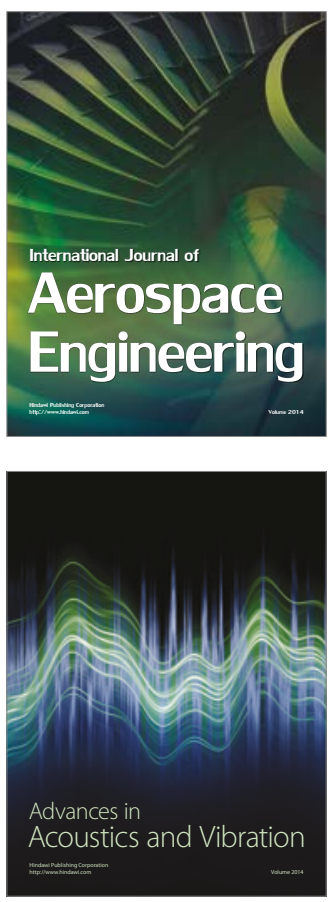

Sensor Networks 